\title{
Prototipo de un sistema para monitoreo de niveles de cauces
}

\section{Prototype of a system for monitoring river levels}

\author{
ESPINOSA-GUERRA, Omar*†, HERNÁNDEZ-LÓPEZ, Dalia Rosario, LÁRRAGA-ALTAMIRANO, \\ Hugo René y PIEDAD-RUBIO, Ana María
}

Tecnológico Nacional de México - Instituto Tecnológico de Ciudad Valles, Carretera al Ingenio Plan de Ayala Km. 2 , Colonia Vista Hermosa, C.P. 79010, Ciudad Valles, S.L.P.

ID $1^{\text {er }}$ Autor: Omar, Espinosa-Guerra / ORC ID: 0000-0002-5787-226X, Researcher ID Thomson: W-7585-2019, arXivAuthor ID:omar_espinosa , CVU CONACYT ID: 37672

ID $1{ }^{\text {er }}$ Coautor: Dalia Rosario, Hernández-López / ORC ID: 0000-0002-2751-5886, Researcher ID Thomson: T-2470-2018, arXivAuthor ID: DaliaHernandez, CVU CONACYT ID: 536472

ID $2^{\text {do }}$ Coautor: Hugo René, Lárraga-Altamirano / ORC ID: 0000-0001-8258-9418, Researcher ID Thomson: T-2296-2018, arXivAuthor ID: Hugo_Larraga, CVU CONACYT ID: 626539

ID $3{ }^{\text {er }}$ Coautor: Ana María, Piedad-Rubio / ORC ID: 0000-0003-1258-0383, Researcher ID Thomson: T-2477-2018, arXiv Author ID: ampiedad, CVU CONACYT ID: 732279

DOI: $10.35429 /$ JTO.2019.11.3.30.39 Recibido 10 de Junio, 2019, Aceptado, 30 de Septiembre, 2019

\section{Resumen}

Se presenta el prototipo de un sistema de monitoreo para medir el incremento del nivel de cauce de los ríos para la prevención oportuna ante una contingencia de inundación. Son utilizadas plataformas de hardware y software abiertas, que permiten la integración y cambio de módulos de sensores para incrementar las funcionalidades y alcances, además emplean protocolos de comunicación estándar que facilitan la escalabilidad y reconfiguración de los nodos. Se contempló un sistema de abastecimiento de energía solar, que garantizara el funcionamiento de manera continua, incluye también la transmisión de datos en tiempo real usando tecnologías inalámbricas. Como Sistema de Alertas Tempranas su función principal es reducir o evitar los daños producidos por amenazas de inundaciones. La Zona Huasteca tiene gran cantidad de ríos los cuales suelen estar cerca de zonas pobladas o asentamientos, en épocas de lluvia la mayoría son propensos a crecer de manera repentina y exponencial. Las pruebas de funcionamiento del prototipo se realizaron en un ambiente controlado, identificándose el proceso apropiado para la recolección, lectura y transferencia de datos, así como su interpretación. La tecnología presentada es viable para su implementación, permite la integración de mas sensores que podrían conformar una red de monitoreo de mayor alcance.

\begin{abstract}
It's presented the prototype of a monitoring system to measure the increase in the level of course of rivers for the timely prevention before a contingency of flooding. Are used hardware and software open platforms, which allow the integration and exchange of sensor modules to increase the functionality and scope, they also employ standard communication protocols that facilitate the scalability and reconfigurability of the nodes. It's considered a solar system cells to supply energy ensuring continuous operation, also includes a real-time data transmission using wireless technology. As an Early warning System its main function is to reduce or prevent the damage caused by threats of floods. The Huasteca area has a large amount of rivers, which tend to be near populated areas or settlements, in times of rain, the majority are likely to grow suddenly and exponentially. The functional tests of the prototype were conducted in a controlled environment, identifying the appropriate process for the collection, reading and transfer of data, as well as their interpretation. The technology presented is feasible for their deployment, it allows the integration of more sensors that could form a monitoring network of larger scope.
\end{abstract}

Monitoring, Automation, Sensor network

\footnotetext{
* Correspondencia del Autor (Correo electrónico: omar.espinosa @ tecvalles.mx)

$\dagger$ Investigador contribuyendo como primer autor.
} 


\section{Introducción}

El estudio de los fenómenos meteorológicos extremos debe considerar a los seres humanos como parte del sistema hidrológico, ya sea como agentes de cambio o como beneficiarios de los servicios ecológicos. Estos fenómenos pueden afectar en lo que refiere a daños y pérdidas económicas causadas por desastres relacionados con el agua, tales como inundaciones, sequías, derrumbes y hundimientos debido a diversos factores, tanto naturales como sociales (entre ellos el cambio poblacional y el desarrollo económico). Es necesario identificar medidas apropiadas y oportunas de adaptación en un medio ambiente en continuo cambio. Además, es necesario mejorar la capacidad para establecer predicciones a través de sistemas de alerta temprana favoreciendo las cuencas sin sistemas de medición. (UNESCO, 2019)

Una red de sensores inalámbricos o WSN (Wireless Sensor Network) se compone de una serie de sensores de diversos tipos distribuidos, espacialmente interconectados por una red de comunicaciones inalámbrica formando nodos, los que monitorizan de forma cooperativa condiciones físicas o ambientales. (Aakvaag \& Frey, 2006)

Una WSN por sus características puede ser parte de un Sistema de Alertas Tempranas (SAT) quien tiene componentes esenciales asociados a recopilación de datos, control, detección y reacción ante riesgos en el entorno, siendo esta la tecnología capaz de ofrecerlos.

El SAT es un dispositivo importante ante fenómenos naturales, parte en anticipar con cierto nivel de certeza, tiempo y espacio, una amenaza natural o generada por la actividad humana. Permitiendo su vigilancia, monitoreo y la activación de los canales de comunicación establecidos, para la alerta oportuna a la sociedad. (Huaman, 2019)

Un SAT tiene como función principal reducir al mínimo o evitar los daños producidos por amenazas de distinto tipo: al medio ambiente, a los medios de subsistencia y a la humanidad en general. Una de estas amenazas son las inundaciones repentinas, fenómenos hidrológicos que se forman muy rápidamente y son difíciles de predecir.
Estas inundaciones son productos de la combinación de la intensidad y duración de la precipitación y el proceso de producción de escorrentía rápida, además de factores hidrológicos, como las características del suelo y las cuencas hidrográficas donde los flujos de escorrentía definen su nivel de riesgo.

De acuerdo con información de un estudio encontrado en la base de datos realizada por OFCA-CRED Database (OFCA CRED, 2019), las inundaciones son el peligro natural más frecuente a nivel mundial. En el 2018 ocurrieron 127 desastres hidrológicos, que mataron a 2,879 y afectaron a 34.2 millones de personas en el mundo, causando un perjuicio económico enorme, de 19.7 billones de dólares en perdidas por esta situación.

La Zona Huasteca es conocida por su gran cantidad de ríos, muchos de los cuales son gran atractivo turístico, aunque también suelen estar cerca de zonas pobladas o asentamientos; los cuales durante las épocas de lluvia corren el riesgo de sufrir algún daño ocasionado por el incremento en el cauce de éstos ya que, la mayoría son propensos a crecer de manera repentina y exponencial.

En años pasados en Ciudad Valles han ocurrido gran cantidad de inundaciones en distintas colonias ubicadas cerca de los cauces de ríos, provocando con ésto la pérdida tanto de bienes materiales, como el riesgo de muerte para los habitantes de dichos lugares, los cuales son un total de 47 colonias, en donde la más aquejada es Praderas del Río, presentando inundaciones en las calles Río Grijalba, Río Jordan, Río Grande, Av. Santa Rosa, Río Nazas, Río Belga, Río Sena, Río Missisipi, Río Nilo, Río Rhin.

Por lo anterior, se propuso la realización de un prototipo de un sistema de monitoreo que automatiza el proceso de obtención de datos en tiempo real sobre el incremento en el nivel de cauces de los ríos. Por medio de los datos recibidos se evalúa a través de un software dicha información, que permitirá una pronta o anticipada respuesta para la difusión y prevención de dicha amenaza. 


\section{Antecedentes}

El trabajo denominado "Implementación de un prototipo de sistema electrónico mediante comunicación inalámbrica para supervisión y detección de inundaciones", desarrollado en Riobamba - Ecuador, cuyo objetivo fue el de implementar un prototipo de sistema electrónico mediante comunicación inalámbrica para supervisión y detección de inundaciones, concluyó que el sistema es preciso y recomendó para trabajos futuros la inserción de cámaras web para una visualización inmediata cuando suceda el evento. (Proaño \& Suarez, 2016)

En México se presentó la "Propuesta de Diseño de un Sistema de Alerta Temprana por Inundación en la Subcuenca del Río Tejalpa (SIATI-ScRT)", la cual permite integrar y definir la ubicación de pluviómetros, limnímetros y bocinas que preparen a la población ante una inundación; con el que se podrán tomar medidas anticipadas y oportunas de preparación y respuesta en situaciones de emergencia en contra de las inundaciones. Con el SIATI-ScRT se logra la transmisión de datos pluviométricos en tiempo real, las lecturas de limnímetros que permita el pronóstico de crecidas para las zonas con riesgo de inundación (Mora \& Rosas, 2016).

La República Mexicana, por su ubicación y sus características geográficas está expuesta a la presencia de fenómenos hidrometeorológicos (principalmente ciclones tropicales), tales como inundaciones fluviales y costeras, vientos intensos, ondas de frío y de calor, nevadas, granizadas, etc. Relacionadas a estos fenómenos también se presentan lluvias fuertes $y$ torrenciales de alta intensidad, y de poca duración que provocan inundaciones y deslaves. (Protección Civil, 2017)

La Coordinación Municipal de Protección Civil de Ciudad Valles quien conjuntamente con el Consejo Municipal de Protección Civil se encarga de la prevención, mitigación, auxilio y apoyo a la población ante la amenaza de riesgo o la eventualidad de catastrofes, calamidades o desastres (Reglamento de Protección Civil, 2009).
Esta dependencia realizó un estudio, que ha servido como base para el presente trabajo, se localizaron corrientes intermitentes que en época de lluvias llegan a manifestar problemas en la zona urbana de Cd. Valles, debido principalmente a que en el punto de confluencia con el río Valles, al encontrarse éste crecido, se produce un remanso hidráulico, al no poder ingresar los afluentes a la corriente principal; el flujo hidráulico retrocede hacia aguas arriba provocando inundación en las zonas bajas, ver Tabla 1.

\begin{tabular}{|c|c|c|c|}
\hline Lugar & Casas & $\begin{array}{l}\text { Person } \\
\quad \text { as }\end{array}$ & Tipo \\
\hline Fracc. Praderas del Río & 1158 & 3638 & Creciente del río \\
\hline Zona Centro & 341 & 1142 & Encharcamiento \\
\hline Col. Juárez & 131 & 496 & Creciente del río \\
\hline Col. La Diana & 105 & 384 & Creciente del río \\
\hline Col. Márquez & 102 & 350 & Arroyo \\
\hline Fracc. Villas del Rio & 88 & 319 & Creciente del río \\
\hline Col. Hidalgo & 86 & 301 & Creciente del río \\
\hline Fracc. El Carmen & 83 & 219 & Arroyo \\
\hline Fracc. El Campo & 76 & 216 & Encharcamiento \\
\hline Col. Magisterial & 71 & 216 & Arroyo \\
\hline Col. Francisco Villa & 75 & 208 & Encharcamiento \\
\hline Col. 18 de Marzo & 61 & 195 & Arroyo \\
\hline Fracc. El Consuelo & 74 & 185 & Arroyo \\
\hline Col. Obrera & 55 & 162 & Arroyo \\
\hline Fracc. Morelos y Pavón & 53 & 154 & Encharcamiento \\
\hline Col. Cuauhtémoc & 46 & 146 & Creciente del río \\
\hline Col. Santa María & 45 & 131 & Encharcamiento \\
\hline $\begin{array}{l}\text { Fracc. Lomas } \\
\text { Mirador }\end{array}$ & 32 & 114 & Arroyo \\
\hline Fracc. Rafael Curiel & 24 & 106 & Arroyo \\
\hline Fracc. Lomas Poniente & 29 & 93 & Arroyo \\
\hline Col. La Pimienta & 24 & 66 & Arroyo \\
\hline Col. Guadalupe & 20 & 62 & Encharcamiento \\
\hline Col. La Estación & 15 & 56 & Arroyo \\
\hline $\begin{array}{lll}\text { Fracc. } & \text { Rosas } & \text { del } \\
\text { Tepeyac } & & \\
\end{array}$ & 19 & 52 & Arroyo \\
\hline Fracc. Emiliano Zapata & 19 & 46 & Arroyo \\
\hline Col. Santa Rosa & 12 & 45 & Creciente del río \\
\hline Col. Las Águilas & 7 & 15 & Arroyo \\
\hline \multicolumn{2}{|l|}{ Total de personas en riesgo } & \multicolumn{2}{|l|}{9,117} \\
\hline
\end{tabular}

Tabla 1 Relación de personas, colonias, casas y tipo de fenómeno en los lugares que presentan riesgos de inundación en Ciudad Valles

Fuente (Protección Civil, 2017)

En dicho estudio se elaboraron mapas para determinar el riesgo de inundación fluvial en tres aspectos: la inundación fluvial, la vulnerabilidad social y el factor de exposición, ver Figuras 1,2 y 3 . 


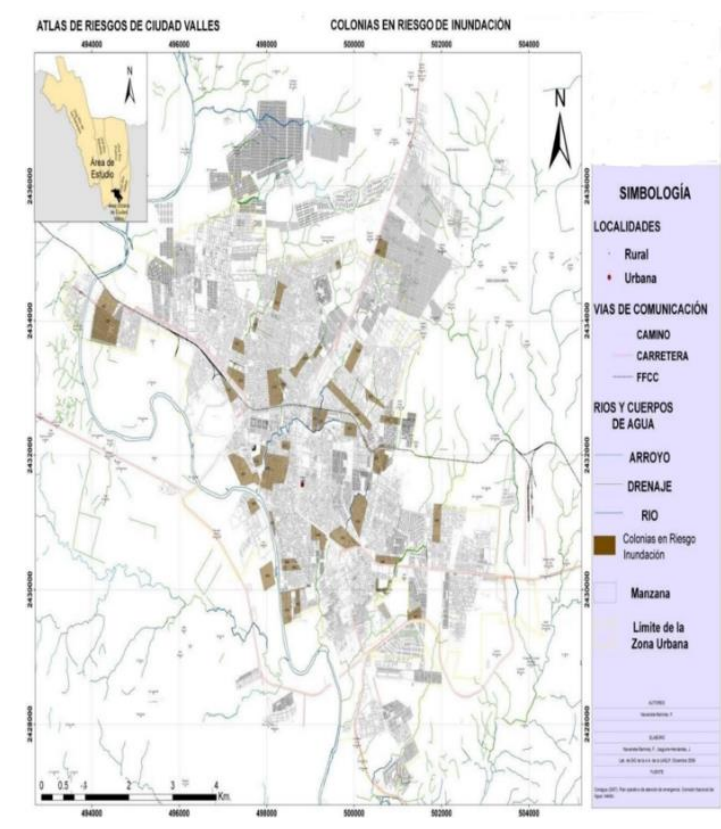

Figura 1 Colonias en Riesgo

Fuente: (Protección Civil, 2017)

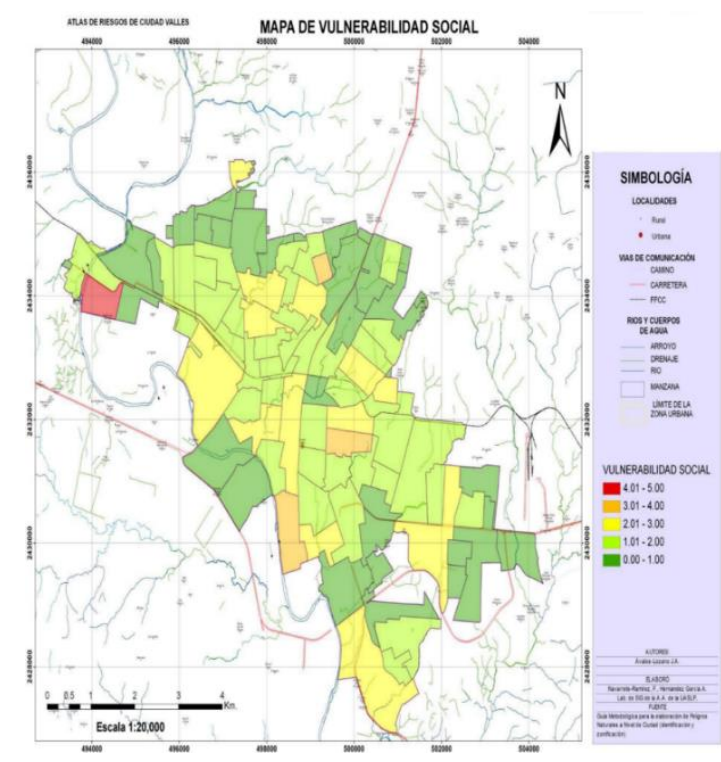

Figura 2 Mapa de Vulnerabilidad Social Fuente: (Protección Civil, 2017)

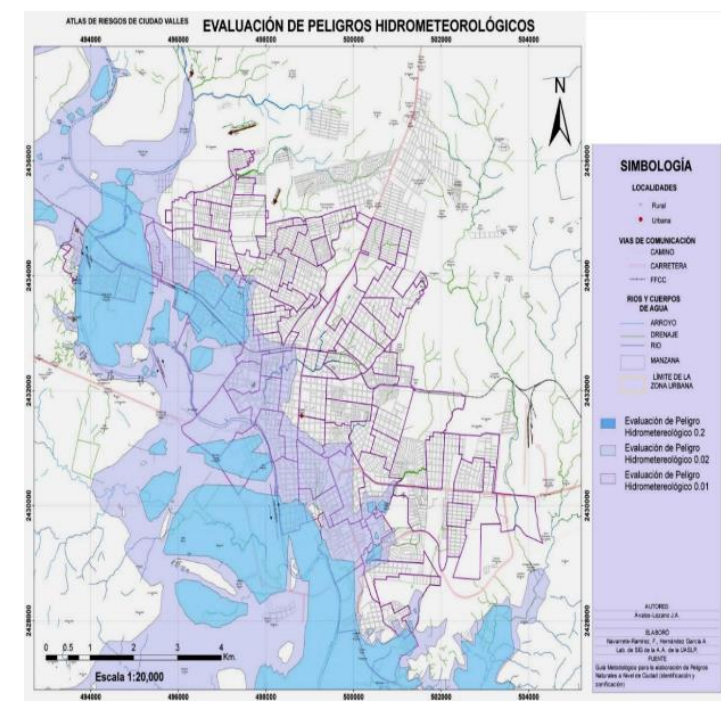

Figura 3 Evaluación de riesgos hidrometereológicos Fuente: (Protección Civil, 2017)
El estudio menciona que después de un análisis de riesgo (amenaza-vulnerabilidad) y con base en los resultados obtenidos, se establecieron inicialmente como zonas de riesgo no mitigables aquellos polígonos que alcanzaron un valor de riesgo de 0.66 a 1.00 . Posteriormente se decide, en este caso, asociar el nivel máximo de riesgo exclusivamente a los niveles de probabilidad de peligro o tasa de excedencia de 0.2 (periodo de retorno de 5 años); descartando el inverso del índice de marginación de 1.0; y el factor de exposición de 5.0. Esto se debe a que la probabilidad de inundación es tan alta que permite despreciar los otros dos factores, ver Figura 4, el estudio sugiere que la población que habita actualmente estas áreas debería ser transferida a un sitio con riesgo menor de acuerdo con el mapa proporcionado.

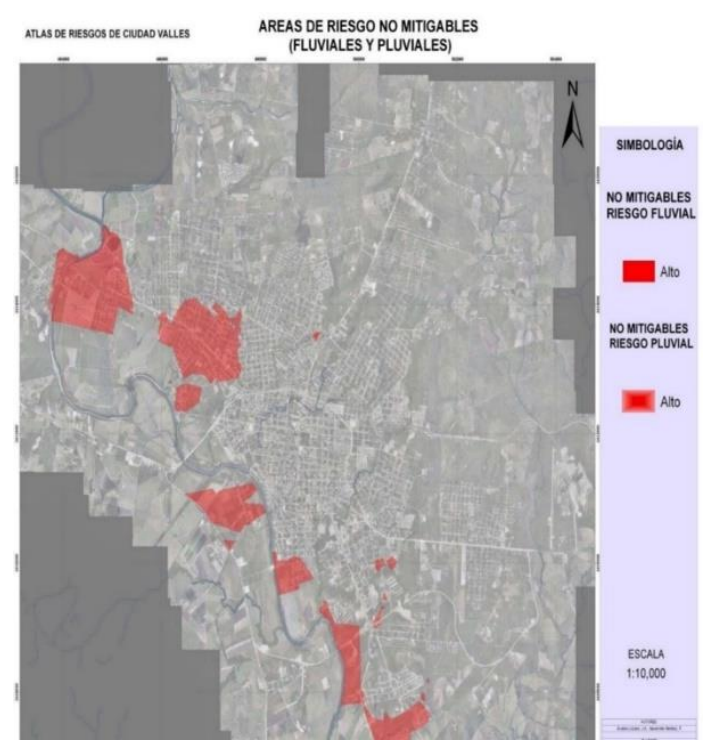

Figura 4 Áreas de riesgo no mitigables Fuente: (Protección Civil, 2017)

\section{Metodología a desarrollar}

1. Recopilación y Análisis de la información El área de estudio se encuentra en la Región Hidrológica No. 26 (Pánuco). Ésta tiene una extensión total de 84,956 km2 (en nueve estados del país), en el Estado de San Luis Potosí ocupa un área de 23,503 km2. La zona urbana de Ciudad Valles se localiza en la parte baja (valle) de la subcuenca Río Valles, tiene influencia de cuatro unidades hidrológicas (Río Valles, Río Mesillas, Río Puerco y Río Los Naranjos). El área de influencia se determina de acuerdo a la hidrografía de las cuatro cuencas señaladas que contribuyen al caudal del río Valles en la parte de la zona urbana. (Protección Civil, 2017) 
En base al documento proporcionado por Protección civil, se identificó que el total de personas en riesgo de acuerdo a este estudio es de 9,117 de 177,022 que es el total de la población en Ciudad Valles, lo cual representa un 5\% de la población que se encuentra en riesgo (INEGI, 2015) .

Se revisó que en la estrategia para enfrentar inundaciones durante la emergencia de la Comisión Nacional del Agua (CONAGUA) en la Ciudad de Valles se tienen fundamentadas diversas acciones, se describen algunas en este apartado:

- Se dará seguimiento de la información hidroclimatológica y emitirá boletines informativos del tiempo a corto plazo de las lluvias diarias y evolución de los niveles de los ríos y presas, así como del almacenamiento y desfogue de la presa Las Lajillas, manteniendo informado al Centro Estatal de Operación.

- Inspeccionará los bordos de protección, brindando asesoramiento técnico en caso de requerir reforzamiento.

En caso necesario apoyará labores de evacuación y rescate.

Continuarán las guardias las 24 hrs. durante el período de emergencia.

Realizará con las Subdirecciones de Asistencia Técnica Operativa y Consejos de Cuenca y Atención de Emergencias y demás Dependencias y Organismos, inspecciones de seguridad en la Infraestructura Hidráulica más importante.

Establecerá la coordinación con otras áreas y organismos con el objeto de recibir información y organizar a las brigadas con recursos y materiales de apoyo para operación de la red hidroclimatológica. (Protección Civil, 2017)

De acuerdo al listado de acciones anteriores, se observa que no se muestra acción documentada en las cuales se tenga el apoyo de algún sistema automatizado de alerta temprana. Durante la revisión del atlas de riesgos se encontró detallada la cronología de inundaciones de 1951 al 2015 a partir de fuentes hemerográficas.
Se acotó la información al identificar los nombres de eventos pluviales y los ciclones tropicales que afectaron a $\mathrm{Cd}$. Valles durante el periodo 2000-2015, los cuales indica que fueron obtenidos después de trasponer la información de lluvias máximas y de avenidas máximas con las fechas de desarrollo de dichos ciclones mediante consultas a los archivos del Servicio Meteorológico Nacional. ver Tabla 2.

\begin{tabular}{|l|l|}
\hline \multicolumn{1}{|c|}{ Fecha } & \multicolumn{1}{|c|}{ Eventos } \\
\hline 29-04-2000 & $\begin{array}{l}\text { Intensa precipitacion causo daños y } \\
\text { caos en cd. Valles, provocando caida } \\
\text { de árboles, anuncios y apagones }\end{array}$ \\
\hline $05-09-2007$ & $\begin{array}{l}\text { Huracán "Dean" deja 15,000 } \\
\text { damnificados y se daclara desastre } \\
\text { natural en 17 municipios }\end{array}$ \\
\hline $08-07-2008$ & $\begin{array}{l}\text { Lluvias intensas provocan } \\
\text { inundaciones en varios puntos de la } \\
\text { ciudad y fallecen 2 personas }\end{array}$ \\
\hline 08-07-2010 & $\begin{array}{l}\text { Las lluvias prolongadas provocan el } \\
\text { crecimiento del río causando reflujo en } \\
\text { los arroyos }\end{array}$ \\
\hline $12-09-2013$ & $\begin{array}{l}\text { Alerta por parte de los habitantes de la } \\
\text { colonia "Tetuan" por crecimiento en el } \\
\text { caudal del río }\end{array}$ \\
\hline \\
$\begin{array}{l}\text { Huracan Ingrid eleva los niveles de los } \\
\text { rios provocando inundaciones }\end{array}$ \\
\hline
\end{tabular}

Tabla 2 Cronología de inundaciones del 2000 al 2015 Fuente: (Protección Civil, 2017)

En la revisión documental se encontró el análisis de los registros históricos de (19592016) de las escalas observadas en la estación hidrométrica Santa Rosa para identificar los niveles hídricos que rebasaron la escala crítica de $5.50 \mathrm{~m}$. Según la CONAGUA, la escala crítica indica el nivel a partir del cual inician las inundaciones de la zona urbana de Ciudad Valles y corresponde a la elevación $77.71 \mathrm{msnm}$, la principal referencia es el parque Luis Donaldo Colosio, ubicado en la margen izquierda del río. Resultó evidente que los ciclones no son responsables de todas las avenidas e inundaciones históricas (Protección Civil, 2017).

Como ya se hizo referencia previa, que en esta ciudad no se cuenta con algún dispositivo de comunicación de alerta temprana ante un desborde o algún prototipo electrónico para esta función, se consideró hacer una propuesta de implementación del prototipo, proponiendo los lugares en los cuales sería recomendable colocarlos, las tres zonas principales serían: Praderas del Río, Col Juárez y Col. Hidalgo, que son las que mayor riesgo tienen por este fenómeno en cuanto a cantidad de población. 


\section{Diseño del prototipo}

Como parte de los trabajos del proyecto, se identificaron los elementos principales que se debían conformar dentro del prototipo y se definieron las funcionalidades, ver Figura 5.

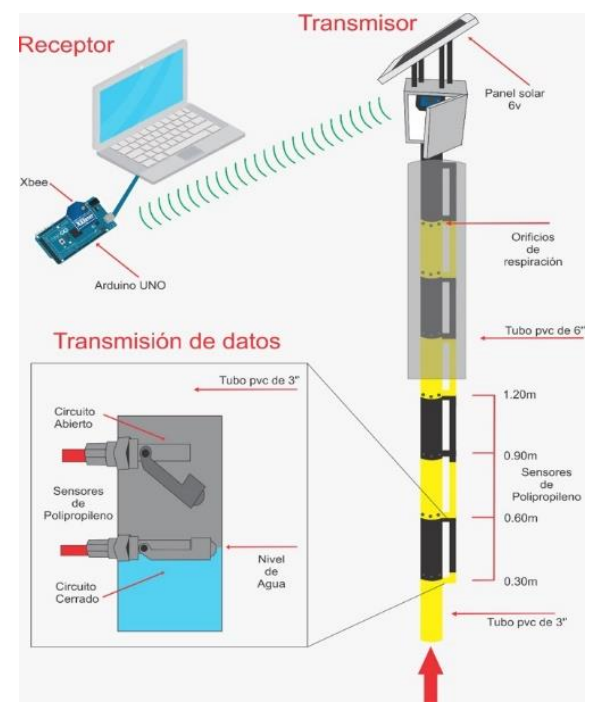

Figura 5 El prototipo desarrollado Fuente original

Un dispositivo para medir niveles a través de flotadores Reed-Switch de polipropileno, debido a su posición horizontal de montaje lateral estos flotadores utilizan un método de pivoteo diferente de otros productos del nivel de flotación. Como un resultado directo de la subida o bajada del agua y ante la proximidad de un campo magnético un interruptor se activa, enviando una señal al circuito electrónico del transmisor.

Esas lecturas son interpretadas a través de un arduino, el cual indica el nivel de acuerdo a un programa de comparación de cada una de las señales que envían los sensores de polipropileno. La señal emitida por el arduino se envía al módulo de radio frecuencia Xbee, el cual transmite la señal de nivel detectada al receptor que se encuentra en la estación de monitoreo.

El transmisor está alimentado por medio de una celda solar, conectada a una batería y un regulador de voltaje, el cual provee el voltaje requerido para la operación del mismo, el regulador es utilizado para mantener una señal de voltaje constante, para no afectar el funcionamiento de la señal transmitida.
El receptor se conforma de una computadora con requerimientos mínimos de un Disco Duro de 1 Terabyte de almacenamiento, $8 \mathrm{MB}$ en RAM, procesador i5, Sistema Operativo Windows 10 con una placa Xbee conectada al puerto USB de la computadora, la cual permite la interpretación de la señal de nivel enviada por el transmisor, a través de un programa desarrollado en el Integrated Development Environment (IDE) de Arduino para mostrar gráficamente el nivel de agua.

\section{Desarrollo del prototipo}

Se eligieron los materiales y componentes para desarrollar el prototipo tanto para el transmisor como para el receptor, en base al diseño propuesto se fueron conectando e instalando, posteriormente se configuraró cada uno y se realizaron pruebas de comunicación entre los módulos, así como el funcionamiento con los diferentes niveles a considerar de colocación de los sensores.

\section{Resultados}

Para el transmisor, primeramente se colocaron los 7 sensores de nivel en un de Tubo PVC de 3", separados cada $30 \mathrm{~cm}$ uno del otro. Al subir el nivel del agua se van cerrando los circuitos y el transmisor envía una señal vía radio frecuencia al receptor, ver Figura 6.

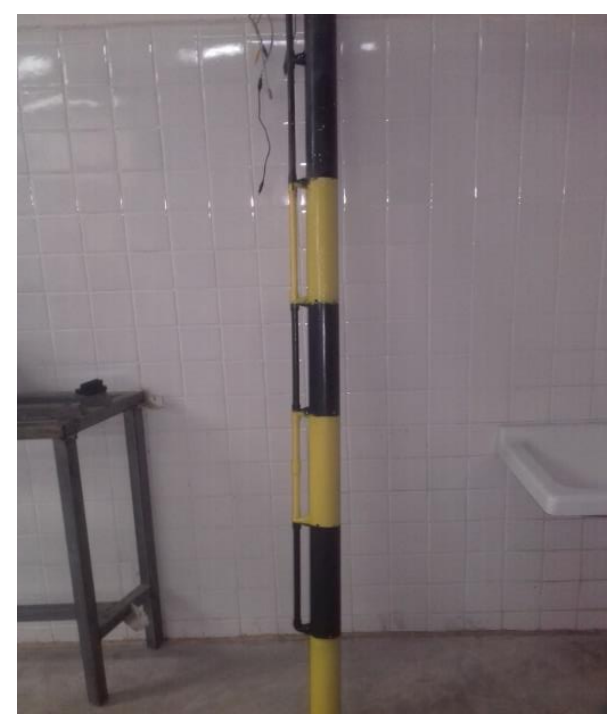

Figura 6 Dispositivo sensor

Fuente original 
Una vez realizada la actividad anterior se procedió a colocar en la parte superior del tubo un gabinete con los siguientes elementos para poder transmitir la señal del nivel del agua, en el interior del gabinete se colocó: un arduino para interpretar la lectura del nivel a transmitir, un controlador de carga solar que regula el voltaje de alimentación, una batería de 12 volts para energizar los sensores de nivel y al arduino, ver Figura 7.

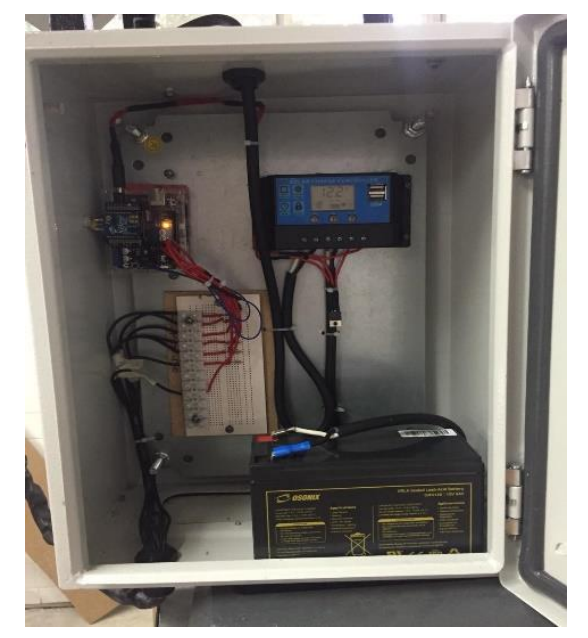

Figura 7 Gabinete con los dispositivos de transmisión Fuente original

Posteriormente, se ancla con unas ménsulas el panel solar policristalino de 20 watts, con voltaje máximo de potencia de 18 volts a 1.1 amperes en la parte superior del gabinete, ver Figura 8.

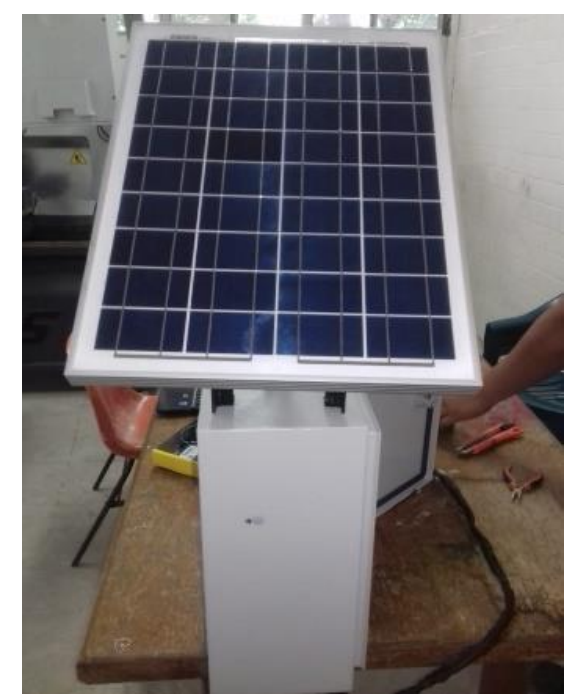

Figura 8 Panel solar instalado sobre el gabinete del transmisor

Fuente original
Finalmente se muestra en la Figura 9 el gabinete terminado con los elementos colocados fuera y dento de él.

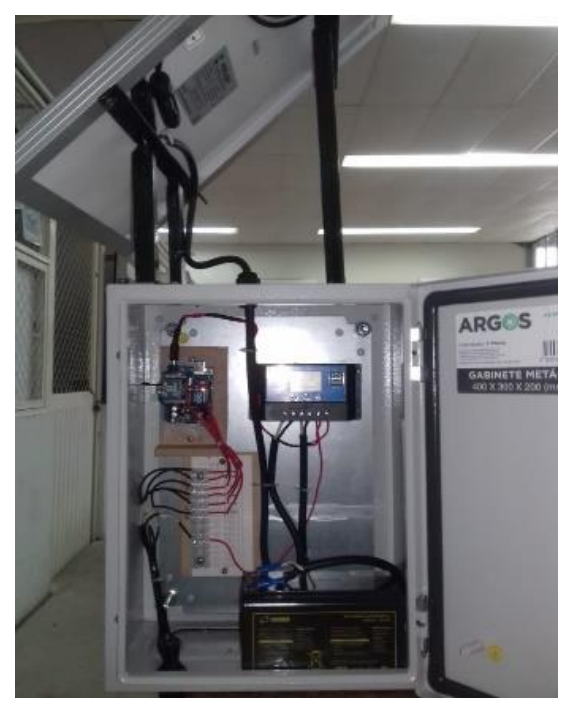

Figura 9 Vista frontal del gabinete terminado Fuente original

De igual manera se procede a configurar el receptor, se conecta el módulo Xbee ensamblado con el escudo directamente al puerto USB de la computadora. Para configurar el módulo como receptor a través del programa XCTU, ver Figura 10.

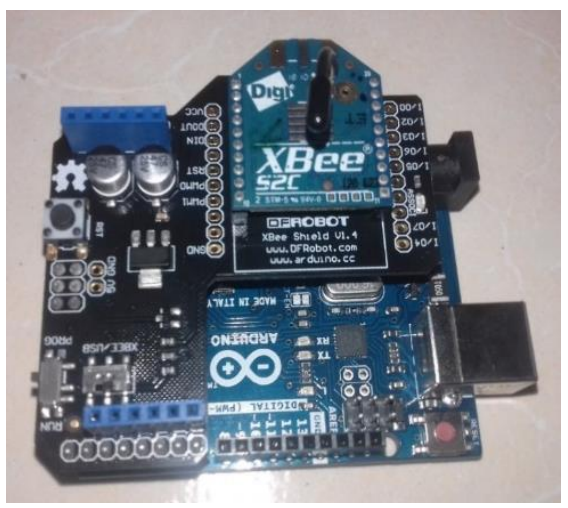

Figura 10 Modulo XBee ensamblado en el escudo Fuente original

Una vez terminados de instalar y configurar tanto el receptor como el transmisor se procede a realizar una prueba de comunicación entre módulos, ver Figura 11. 


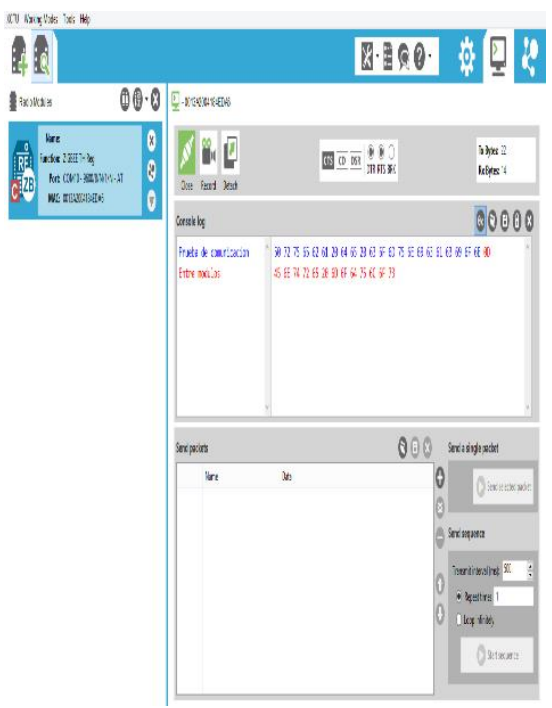

Figura 11 Prueba de comunicación entre módulos Fuente original

En la Figura 12 se muestra la prueba de envío de información con los módulos XBee conectados a los sensores. Representan los centímetros de agua que se están registrando en el transmisor por cada periodo de tiempo de 5 segundos.

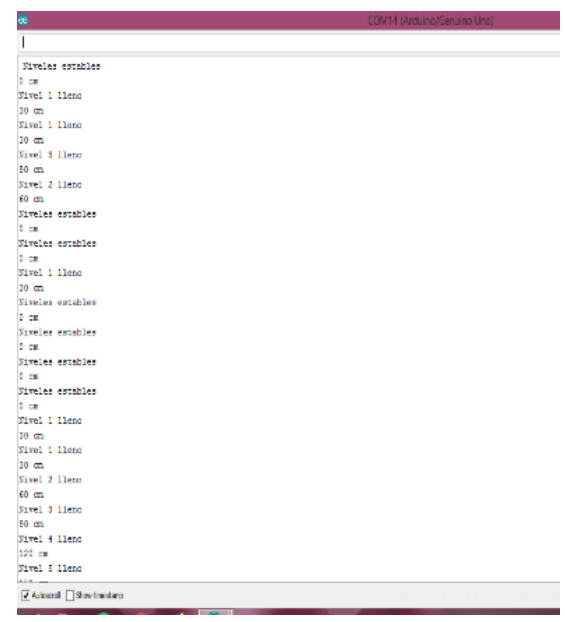

Figura 12 Monitor serial del Arduino IDE Fuente original

En la Figura 13, se muestra la misma información de la imagen anterior, pero en formato gráfico.
Septiembre, 2019 Vol.3 No.11 30-39

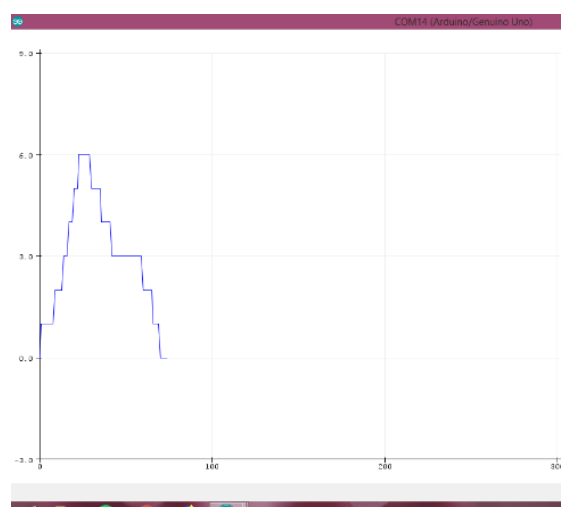

Figura 13 Serial Plotter del Arduino IDE Fuente original

En la Figura 14 se puede observar la prueba final que se realizó sumergiendo el sensor paulatinamente en una cisterna, hasta alcanzar el sexto nivel, es decir a $180 \mathrm{cms}$ de profundidad.

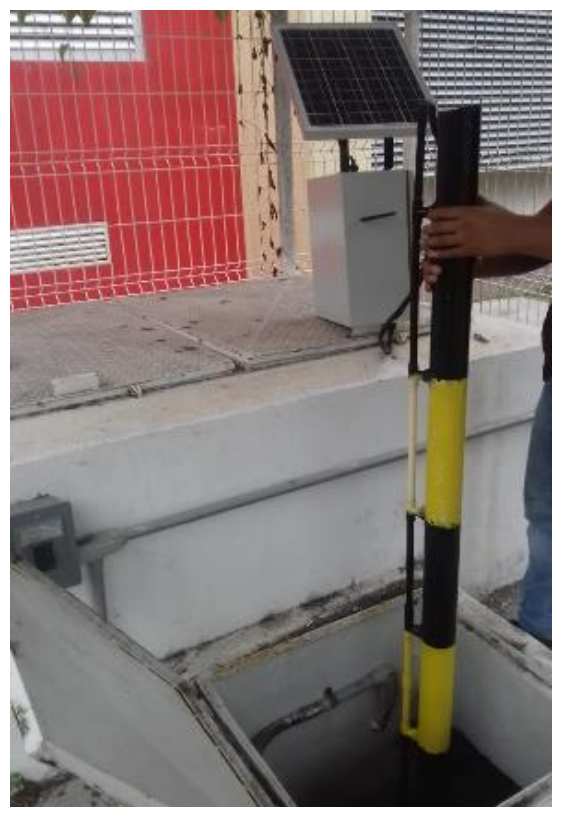

Figura 14 Sensor sumergido en segundo nivel Fuente original

La transmisión de datos se observa en la figura 15, la imagen indica como el nivel del agua llega hasta el cuarto sensor, que equivale a una altura de $120 \mathrm{~cm}$. Esta prueba se realiza repitiendo la acción de sumergir y sacar el prototipo de la cisterna durante 100 segundos, para simular el crecimiento de los cauces en un ambiente real. 


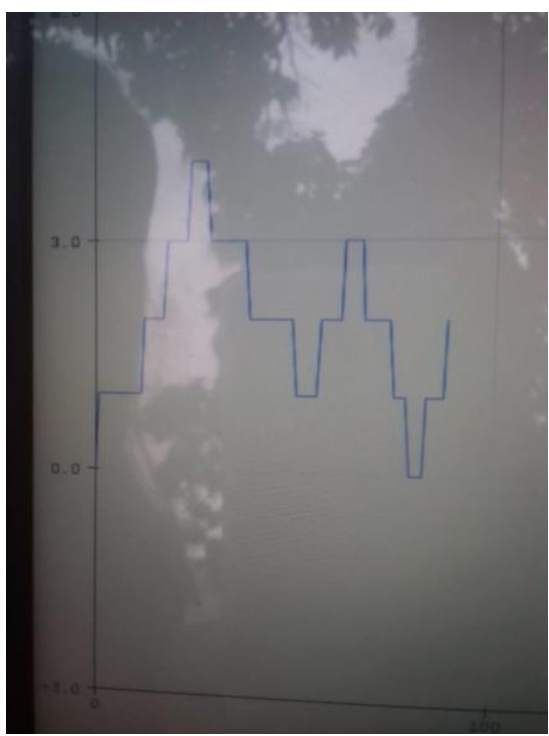

Figura 15 Visualización en pantalla de la transmisión de datos

Fuente original

Las pruebas de alcance de la transmisión de datos desde el módulo de radiofrecuencia se muestran en la figura 16, donde se observa que aún en presencia de obstáculos como construcciones, arboles, colinas, etc. se tiene un radio de 300 metros de alcance, el cual se puede mejorar con una línea directa de visión entre el prototipo y el receptor.

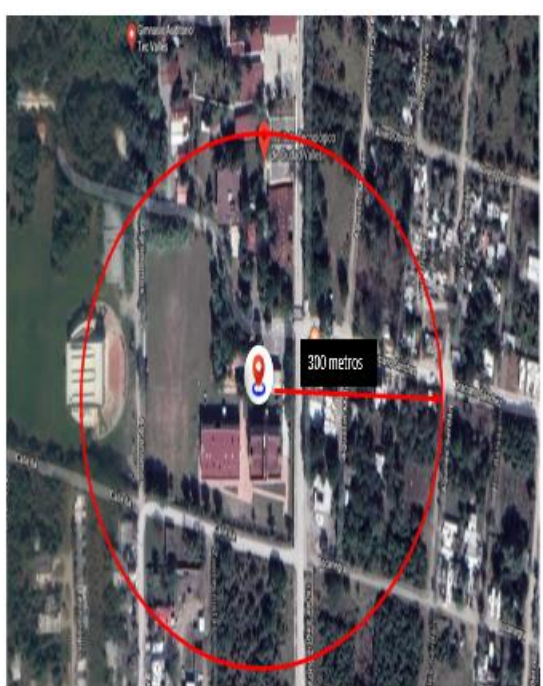

Figura 16 Rango del área de alcance en la prueba Fuente Google Maps

\section{Agradecimiento}

Un agradecimiento al Tecnológico Nacional de México / Instituto Tecnológico de Ciudad Valles por la oportunidad de desarrollar dicho prototipo dentro de las instalaciones.

\section{Conclusiones}

Se ha desarrollado un prototipo de un sistema de monitoreo que automatiza el proceso de obtención de datos en tiempo real sobre el incremento en el nivel de cauces, usando plataformas de hardware y software abiertas que permiten la integración y cambio de módulos de sensores o de comunicación para incrementar las funcionalidades $\mathrm{y}$ alcances del prototipo, empleando protocolos de comunicación estándar que facilitan la escabilidad y reconfiguración de los nodos.

Además, cuenta con un sistema de abastecimiento de energía solar, que garantiza de manera continua y a largo plazo su funcionamiento; e incluye la transmisión de datos en tiempo real usando tecnologías inalámbricas.

En la implementación del prototipo se pudo evidenciar que los sensores de polipropeno son lo suficientemente resistentes y no requieren de un constante mantenimiento.

Con respecto al alcance de la comunicación, como era de esperase la interferencia que provocan los arboles disminuye mínimamente el rango de comunicación entre los Xbee, cabe destacar que la conexión es de punto a punto por tratarse de un prototipo.

La tecnología presentada es viable para su implementación ya que puede adaptarse a la integración de una red más amplia para la monitorización de los cauces.

Aunque el prototipo no require de un mantenimiento frecuente, se recomienda definir los periodos de revisión para cada uno de acuerdo a las condiciones de su ubicación.

La transmisión de datos es totalmente efectiva, pero para zonas mas alejadas es prudente aumentar su alcance con nodos intermedios.

Con una red considerablemente amplia es viable la conexión a una base de datos que almacene los cambios de estado en cada sensor, eso facilitaría el registro de la información para un futuro uso. 
Es necesario que se difundan los beneficios del sistema de alerta temprana, como modelo de aplicación en el futuro, por lo que es recomendable que se realice una coordinación para la prevención de estos eventos por parte de las universidades y centros de investigación que permita incentivar el trabajo conjunto con el sector público y privado.

\section{Referencias}

Aakvaag, N., \& Frey, J.-E. (2006). Redes de sensores inalámbricos Nuevas soluciones de interconexión para la automatización industrial. Revista ABB. Disponible: http://www.ie.com.co/pdf/ABB/02-2006/3942\%25202M631_SPA72dpi.pdf

Ayuntamiento de Ciudad. Valles, S.L.P. (20042006). Plan Municipal de Desarrollo de Cd. Valles, S.L.P.

Bernal, I. (2005). Comunicaciones Inalámbricas. Recuperado 30 octubre, 2018, de https://docplayer.es/74657351-

Comunicaciones-inalambricas-bluetooth-ivanbernal-ph-d.html

DigiKey Electronics | Distribuidor de componentes electrónicos. (s.f.). Recuperado 26 octubre, 2018, de https://www.digikey.com.mx

Huaman, I. (2019). Desarrollo de un sensor para la alerta temprana del desborde del rio seco utilizando arduino en la ciudad de Huaraz 2017. Tesis . Chimbote, Perú.

INEGI. (2015). INEGI. Recuperado el 8 de 03 de 2019, de cuentame: http://cuentame.inegi.org.mx/monografias/infor macion/slp/poblacion/

M2M Communications, Remote Monitoring \& Management - Digi International. (s.f.). Recuperado $26 \quad$ octubre, 2018, https://www.digi.com

Mora, D., \& Rosas, J. (octubre de 2016). Propuesta de Diseño de un Sistema de Alerta Temprana por Inundación en la Subcuenca del Río Tejalpa (SIATI-ScRT). Tesis , 133. Estado de México, México: Universidad Autónoma del Estado de México.
OFCA CRED. (2019). Natural Disasters 2018. Obtenido de Center of Research on the Epidemiology of disasters: https://www.cred.be/publications

Park, C., \& Rappaport, T. S. (2007). Short-range wireless communications for Next-Generation Networks: UWB, $60 \mathrm{GHz}$ millimeter-wave WPAN, and ZigBee. Wireless Communications, IEEE, 14(4), 70-78.

Perucca LP y Paredes JD (2005). Peligro de aluviones en el departamento Pocito, provincia de San Juan. Revista de la Sociedad Geológica Argentina, Vol. 60, no. 1, 48-55 pp.

Proaño, J., \& Suarez, M. (2016). Implementación de un prototipo de sistema electrónico mediante comunicación inalámbrica para supervisión y detección de inundaciones. Tesis . Rio Banba, Ecuador: Escuela Superior Politécnica de Chimborazo.

Protección Civil. (2017). Atlas de Riesgos. 292. Ciudad Valles, San Luis Potosí, México.

Tanenbaum, A.S. (2003). Redes de computadoras. México: Person Educación.

Reglamento de Protección Civil. (2009). Periódico Oficial del Estado Libre y Soberano de San Luis Potosí. Recuperado el 20 de 02 de 2019, de Ayuntamiento de Ciudad Valles 20182021:

http://vallesslp.gob.mx/transparencia/transparen cia/version2/art19/leyes/Proteccion_Civil_Ciud ad_Valles.pdf

UNESCO. (2019). Oficina Regional de Ciencia para América Latina y el Caribe. Recuperado el 10 de 07 de 2019, de Oficina de la UNESCO en MONTEVIDEO:

http://www.unesco.org/new/es/office-inmontevideo/natural-sciences/water-ihplac/water-related-disasters-and-hydrologicalchanges/

XBee.cl. (2015). Módulos de redes inalámbricas. Recuperado el 20 de octubre del 2018, https://xbee.cl/que-es-xbee

ZigBee Alliance. (2015). Protocolo ZigBee. Recuperado el 03 octubre del 2018, http://www.zigbee.org 